\title{
محاولة تكوين البيئة العربية لترقية مهارة الكالام من خلال الدروس الإضافية في مدرسة "أبوذرّ" الثانوية قندال-داندير - بوجونجارا
}

\section{Nurul Musyafa'ah"}

bintakholiq@gmail.com

\section{الملخص}

مشكلة تعليم اللغة العربية هي استيعاب مهارة الكلام للطالبات، ومن أسباها أن المدرسة

أو مكان الدراسة منها لا تطبق ولا توجد البيئة اللغوية. واختارت الباحثة مدرسة أبوذرّ قندال بوجوبحارا لأن المدرسة لم تطبق البيئة اللغوية لممارسة وتكرار الدروس اللغوية، بل إنّ هذه المدرسة إحدى من المدارس الإسلامية و في حيّ المعاهد السلفية. ولقد تعلّم فيها كثير من الطلبة منذ زمان ماض قدر سنة وVY اهـ العلوم الدينية المتنوّعة، وعلوم اللغة العربية بعض من المواد الذي درس فيها الطلبة. ففي هذه الورقة أرادت الباحثة إبراز تلك المحاولة بهدف الإشراح عن تطبيق عملية الدروس الإضافية. وهذا البحث باستخدام المنهج الإجرائي للمدرسة بمجتمع البحث جميع الطالبات ي جميع الفصول والمرحلة وعددها ا. 0 وبجمع البيانات الملاحظة والمقابلة والاختبار.وكانت نتائج البحث هي أن عملية تكوين البيئة العربية من خلال الدروس الإضافية تدور إلى ثلاثة أدوار وتنتج إلى نتيجة جيد وهناك دالة على أن هذه الأنشطة تؤثر تأثيرا قويا لترقية مهارة الكاملام ووجود البيئة العربية.

الكلمات الئيسية: البيئة، الدروس الإضافية

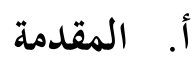

قامت المعاهد والمدارس الإسلامية باندونسيا بتطوير البيئة العربية لتعويد استخدام اللغة العربية. بجانب أنّ فيها تدريس الكتب الدينية التي تستخدم اللغة العربية، وفيها يلزم الطلاب باستعمال اللغة العربية للاتصال اليومي بينهم. فلذلك لتحقيق السيطرة على اللغة العربية شفوية كانت أم تحريرية تحتاج الأشياء المهمة كوسيلة السيطرة عليها وهي البيئة العربية الفعالة.

* محاضرة في جامعة سونان غيري الإسلامية بوجوبنورو 
والبيئة هي كل شيئ خارج نفس الأولاد وتؤثر لتطور اللغة العربية. والبيئة لها دور مهم في تعلم

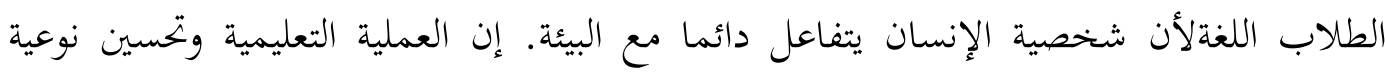

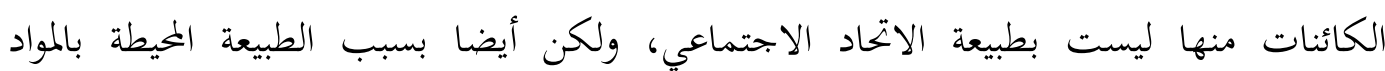

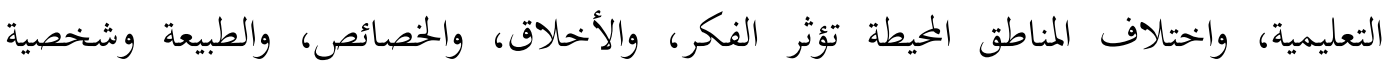

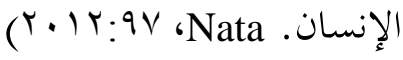

والبيئة العربية هي حالة فيها أنواع من النشاطات اللغوية العربية. إما المحادثة اليومية وإما

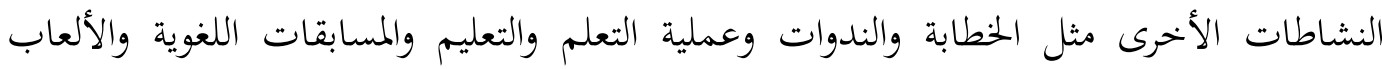

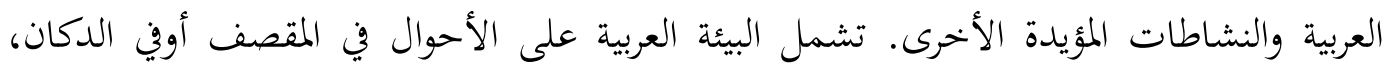

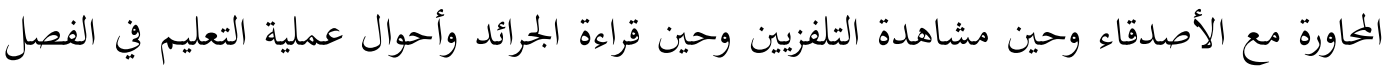
وحين قراءة الدروس وغيرها حتى يستخدم جميع اللغة العربية كوسيلة الإتصال حين تقدم الآراء

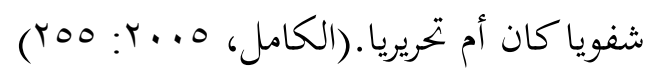

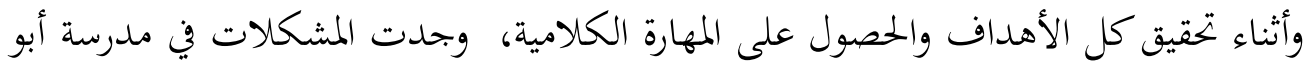

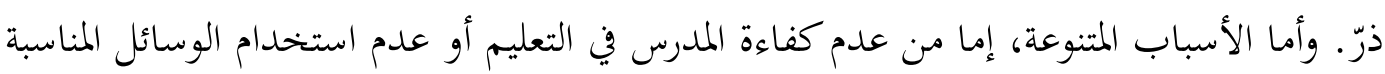

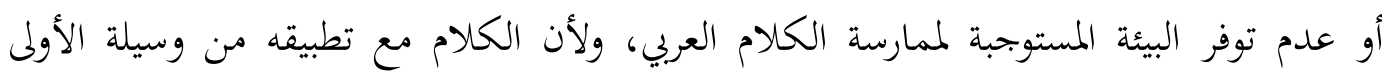

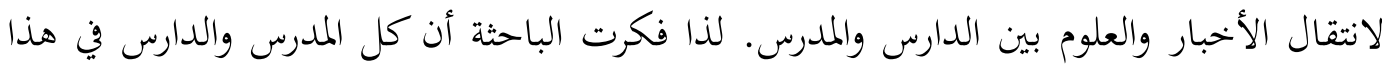
المدرسة يجتاجون إلى البيئة اللغوية لترقية مهارقم الكلامية بينهما.

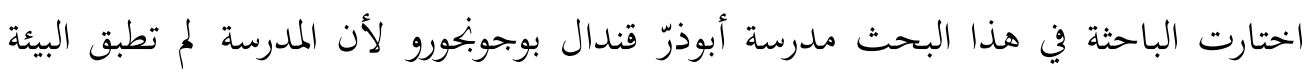

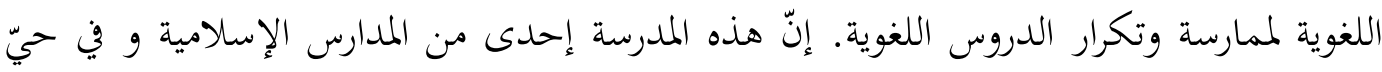

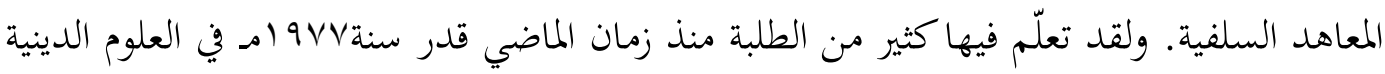

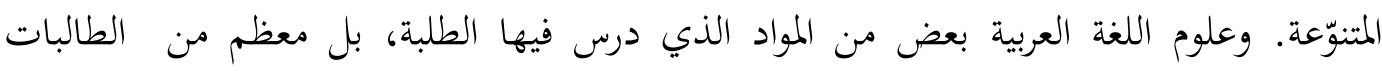

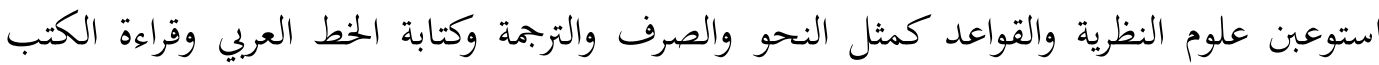
العربية. كذا فكرت الباحثة أن تعليم اللغة العربية فيهالم يكن ناجحا ولم يحصل على درجة الامتياز،

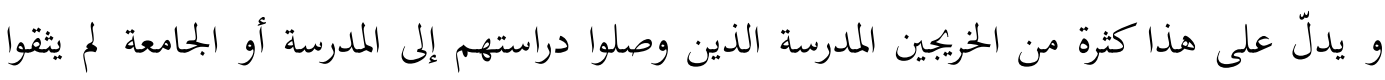
بعلومهم العربية ولم يقدروا على التكلم باللغة العربية. بناء على الأسس السابقة شرحت الباحثة بهذا البحث عن تطبيق عملية وجود البيئة العربية

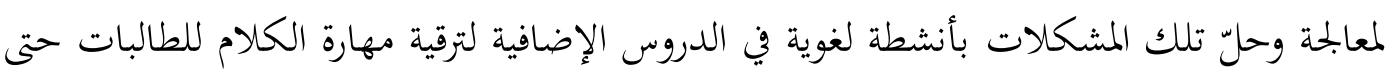

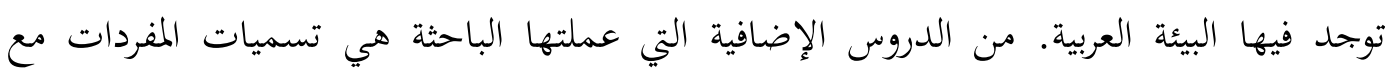


حفظها ثم الغناء العربي والألعاب الشفهية. وعلى هذا فقد حددت الباحثة مشكلة هذا البحث التى تتطلب الإجابة عن الأسئلة الآتية:() كيف محاولة تكوين البيئة العربية لترقية مهارة الكلام من خلال الدروس الإضافية في مدرسة أبوذرّ قندال-داندير-بوجوبكورو؟ץ) وما مدى فعالية تكوين البيئة العربية من خلال الدروس الإضافية لترقية مهارة الكام في مدرسة أبوذّر قندال-داندير - بوجوبحارا؟

\section{ب. مفهوم البيئة العربية واستيراتيجيتها

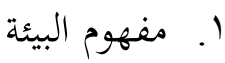

البيئة اللغوية هي كل ما يسمعه المتعلم وما يشاهده مما يتعلق باللغة الثانية المدروسة وأما ما تشتمله البيئة اللغوية هي الأحوال في المقصف أو الدكان، الحوار مع الأصدقاء وحين مشاهدة التلفزيون وحين قراءة الجريدة. الأحوال حين عملية التعلم في الفصل وحين قراءة الدروس وغيرها

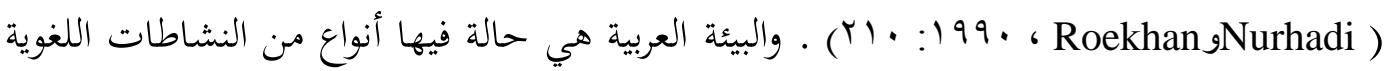
العربية حتى يستخدم جميع اللغة العربية كوسيلة الإتصال حين تقدم الآراء شفويا كان أم تحريريا. إن البيئة عموما تنقسم إلى قسمين: () البيئة الإصطناعية r ب) البيئة غير الإصطناعية (الطبيعية). أما البيئة الإصطناعية لها دور هام لاكتساب اللغة الثانية وهي: (1) يكون متعلم مختلفا في استخدام لغته على حسب الظروف r) يكون متعلم محسنا في استخدام اللغة باعتبار القواعد ؟) هذا التعليم يشبع المتعلم الذي يريد استيعاب القواعد اللغوية أو نظام اللغة عن قواعد اللغة المدروسة، في ناحية أخرى أن سيطرة قواعد اللغة الهدف لا تساعد كثيرا في سيطرة المهارات اللغوية

(IIV:199 • ، Roekhang Nurhadi ). للغة المدف البيئة العربية هي حالة فيها أنواع من النشاطات اللغوية العربية حتى يستخدم جميع اللغة العربية كوسيلة الإتصال حين تقدم الآراء شفويا كان أم تحريريا. وبعد هذه المقدمة الموجزة أرجو أن أشير إلى بيئات تعليم اللغة العربية، وأوها:

أ) البيئة المنظمة: مؤسسات التعليم: يبدأ هذا العمل بمنهج رسم السياسة التعليمية. منهج متكامل يصمم بناء على دراسات موفية للحاجات الإجتماعية من حيث المنطلق العقدي والفلسفي لما يراد من المنهج من توجيه، ودراسات موفية كذلكم للنواحي النفسية والإجتماعية والثقافية وغيرها مما هو محيط بالمتلقي واختيار مواد لتحقيق الحصول على سلى المهارات المطلوبة في كل لغة من استماع وكلام وقراءة وكتابة، وهذه المهارات هي التي تتحقق هما وظيفة اللغة للاتصال المعرين بين أفراد المجتمع وكذلك فائدتا لطالبها مباشرة أو بسبيل الترجمة. 
وأحسب أن البيئة اللغوية تتداح دائرةا لتشمل من بيئة التلقي المباشر من خلال

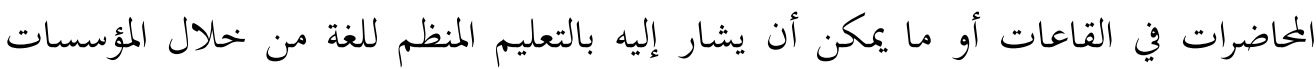

$$
\text { التعليمية من الروضة إلى أعلى المراحل في التعليم الجامعي. }
$$

ب) إعداد المعلم

هو محور العملية التربوية فعلى الدول إعداد المعلم المؤهل المشبع بحب اللغة التى

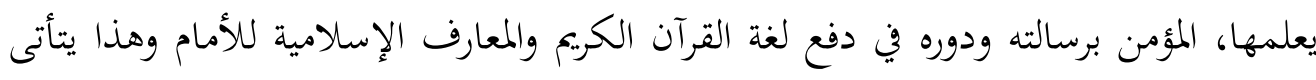

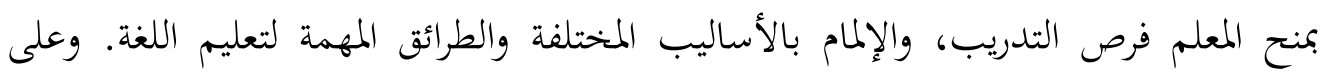

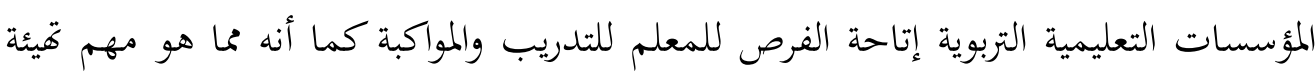

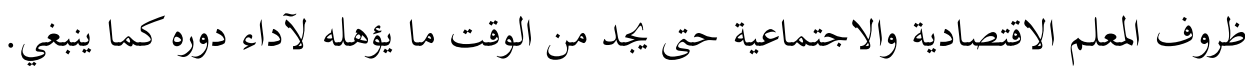

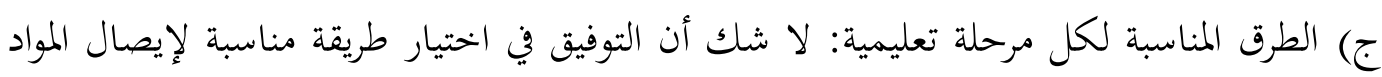
الدراسية مهم للغاية

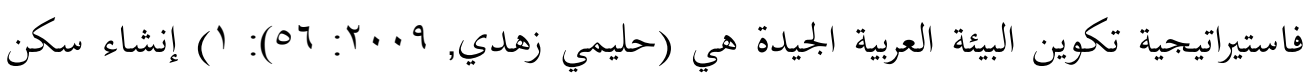

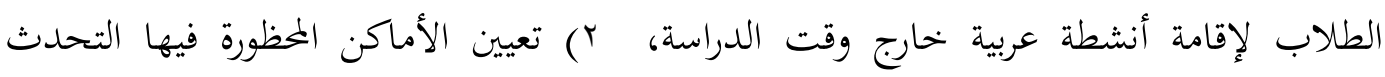

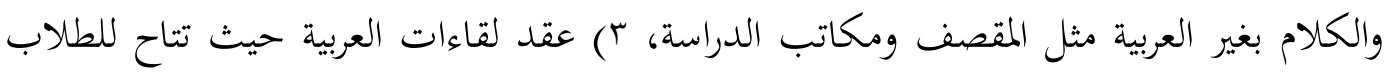

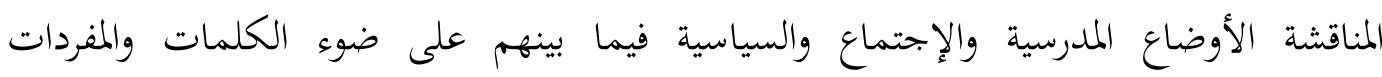

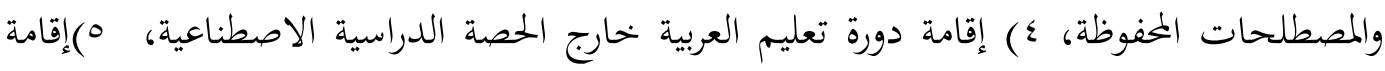

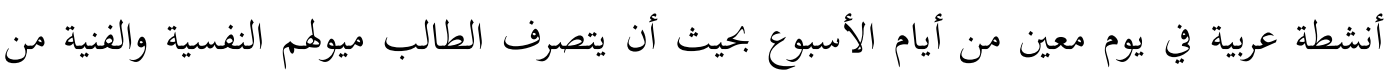

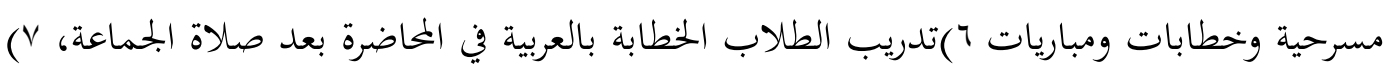

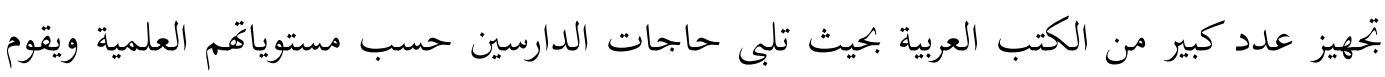

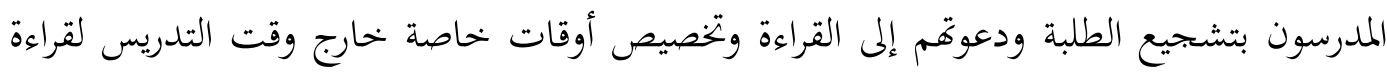

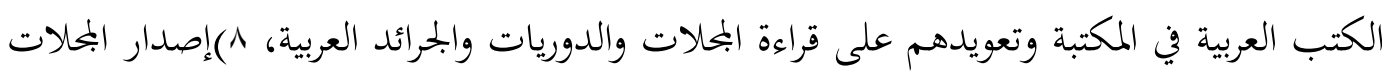

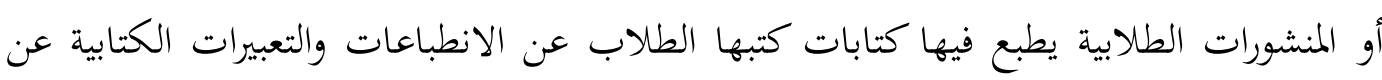

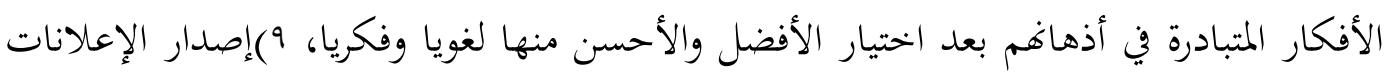

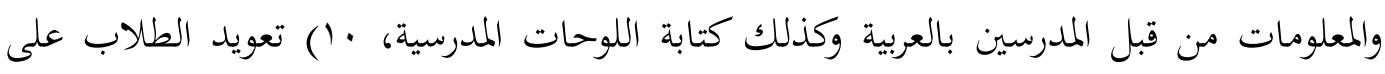

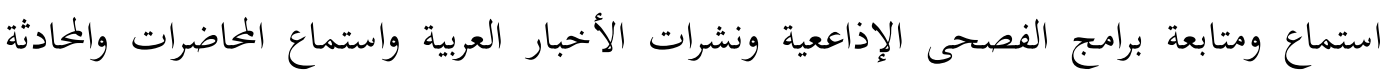

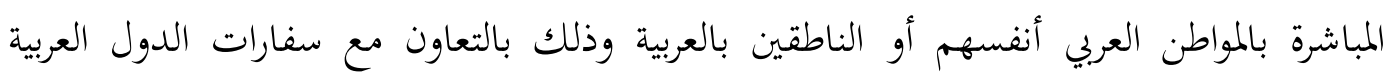

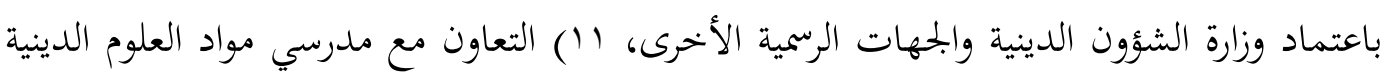
على أن تكون المواد الدينية المدروسة باللغة العربية سهلة العبارات. 


\section{r}

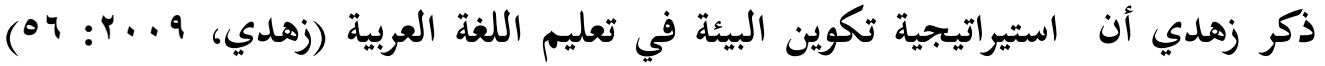
فيما يلي:

أ) إنشاء سكن الطلاب وذلك ليكون الطلاب مركزين في مكان واحد ويسهل على المشرفين والمدرسين مراعتهم وإرشادهم وغقامة أنشطة عربية خارج وقت الدراسة.

ب) تعيين الأماكن المخظورة فيها التحدث والكلام بغير اللغة العربية مثل المقصف ومكاتب الدراسة. ج) عقد لقاءات عربية حيث تتاح للطلاب المناقشة الأوضاع المدارسية والإجتماع والسياسية فيما بينهم على ضوء الكلمات والمفردات والمصطلحات المحفوظة والمدروسة وذلك لتدريب الطالب خارج الفصل الدراسي على الإستماع والتحدث والتعبير الشفهي عن انطباعتهم باللغة العربية تجاه الأوضاع المعاشة واستماع ذلك من أصحابهم.

د) إقامة دورة تعليم اللغة العربية خارج الحصة الدراسة الاصطناعية وذلك لسد ثغرات ناجمة عن قلة زمن حصة العربية داخل الفصل الدراسي وذلك لتزويد الدارسين بثروة لغوية اكثر من الثروات الموجودة داخل الفصل. هـ) إقامة أنشطة عربية في يوم معين من أيام الأسبوع بحيث أن يتصرف الطالب ميولهم النفسية والفنية من مسرحية وخطابات ومباريات وكل هذه الأنشطة أجيرت تحت ضوء اللغة العربية وتحت رعاية وإرشاد المشرفين والمدرسين في اللغة العربية. و ) تدريب الطلاب على القاء الخطابة بالعربية في المحاضرة الوجيزة بعد صلاة الجماعة. ز) هيئة عدد كبير من الكتب العربية بحيث تلبى حاجات الدارسين حسب مستوياتم العلمية ويقوم المدرسون بتشجيع الدارسين ودعوتهم إلى القراءة وتخصيص أوقات خاصة خارج وقت الدارسين لقراءة الكتب العربية في المكتبة وتعويدهم على قراءة المحلات والدوريات والجرائد العربية. ح) إصدار المجلات أو المنشورات الطلابية يطبع فيها كتابات الطلاب عن الانطباعات والتعبيرات الكتابية عن الأفكار المتبادرة على أذهافم بعد اختيار الأفضل والأحسن منها لغويا وفكريا. ط) إصدار الإعلانات والمعلومات من قبل المدرسين بالعربية وكذلك كتابة اللوحات المدرسية. ي) تعويد الطلاب على استماع ومتابعة برامج الفصحى الإذاععية ونشرات الأخبار العربية واستماع المحاضرات والأحاديث الطويلة من العرب أنفسهم وذلك بالتعاون مع سفارات الدول العربية باعتماد وزارة الشؤون الدينية والجهاز الرسمي الآخر. 
ك) التعاون مع مدرسي مواد العلوم الدينية على أن تكون المواد الدينية المدروسة باللغة العربية سهلة العبارات.

\section{r. خصائص البيئة اللغوية الجيدة في ترقية تعليم اللغة العربية.}

إن البيئة عندها أثر قوي لتعليم اللغة العربية وناجحة لسهولة شعار اللغة بالأمور الآتية (زهدي، •؟:9 · [ץ): وجود التعليم والتعلم جذابا ومشوقا بالكالام فصيحا ودوام استخدام اللغة العربية مع الطلاب. وقليل من الشرح والبيان بل كثير من التدريب والتطبيق. وهناك المحاولة للكلمات والمفردات في السبورة أو في الكتب المدرسية واضحة سهلة بسيطة كي لا تشعر الطلاب بصعوبة اللغة العربية فيكرهوا وينفروا عنها. ثم وجود القوانين والأنظمة التي تنظم الطلاب في استعمال وتطبيق اللغة يوميا. وكثير من النشاطات الطلابية اللغوية مثل الخطابات العربية والجرائد والبحلات الحائطية وغيرها وتشرفهم عليها. اشتراك الطلاب في المسابقات بينهم في نفس المدرسة أو مع الطلاب في مدارس الأخرى في اللغة العربية. ع. ع. الدروس الإضافية

الدروس الإضافية من التعليم غير النظامي وهو التعليم من جهة العائلة والبيئة تعني الباحثة أن هذا التعليم عملية مستمرة في الحياة التي فيها حصول النتيجة للشخص على القيمة، والمواقف، والمهارات، والمعرفة المستمدة من بتحارب الحياة اليومية وتأثير مصادر التعليم في البيئة، مثل من الأسرة والأصدقاء، والجيران،والعمل، والمكتبة، والسوق، ووسائل الإعلام وغيرها. وهو كرفاق والدوافع

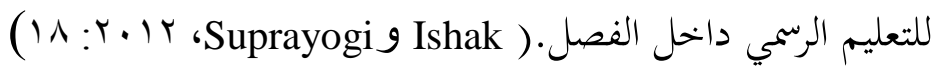
وتوجد أنشطة الدروس الإضافية في كل مستوى من مستويات التعليم من المرحلة الابتدائية حتى الجامعة .الدروس الإضافية للطلاب تمدف لنطوير شخصية الطلاب وموهبتهم، وقدرة الطلاب غير المحالات خحارج الحقل الأكاديمي .تقام هذه الأنشطة بشكل مستقل عن المدرسة والطلاب أنفسهم. هذه الأنشطة يمكن بشكل أنشطة في بحال الفنون، والرياضة، والتنمية الشخصية، وغيرها

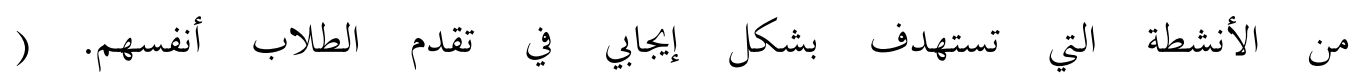
(http://id.wikipedia.org/wiki/Ekstrakurikuler الدروس الإضافية التي تقوم فيها طالبات المدرسة في هذا البحث خارج ساعات في تعلم المنهج القياسي. بمحاولة زيادة الأنشطة اللغوية العربية التي تتعلق بموضوع الدراسة في الفصل. 


\section{•. الأنشطة في الدروس الإضافية

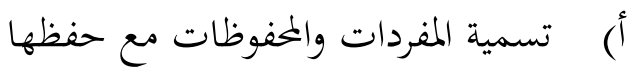

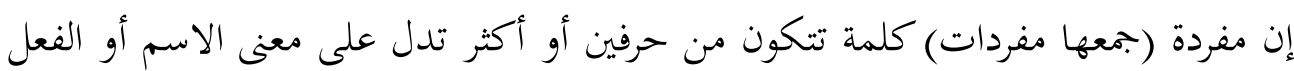

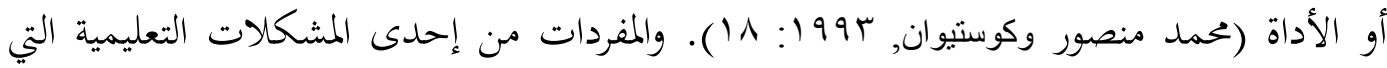

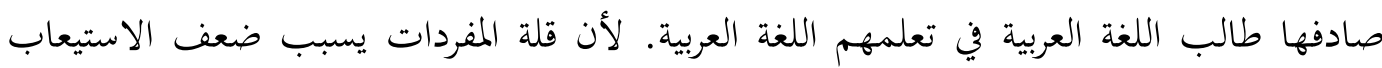

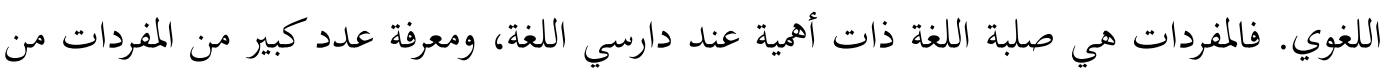
أهم الأشياء في استيعاب القراءة كذلك تؤدي إلى تنمية الثروات اللغوية.

$$
\text { ب) الغناء العربي }
$$

إن الغناء بالموسيقى يؤثّر تأثيرا قويّا للدراسة. من منافع أثر الموسيقى هي إعطاء الدوافع

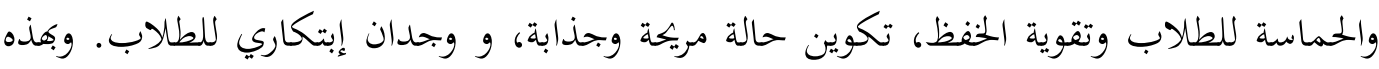

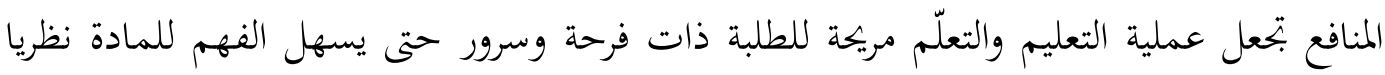

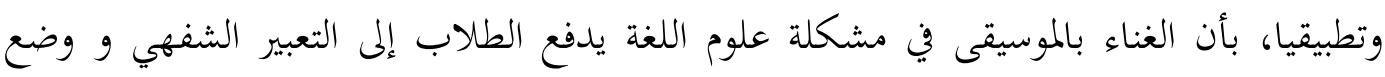

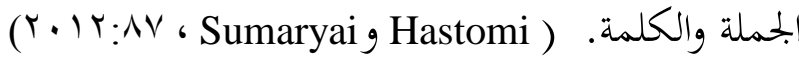

$$
\text { الألعاب اللغوية الشفهية }
$$

الألعاب جمع من "لعب". وهو النشاط الوحيد الذي مارسه الإنسان بالمتعة نتيجة اللعب

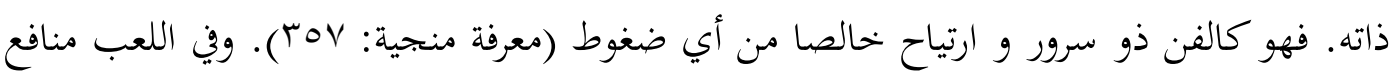

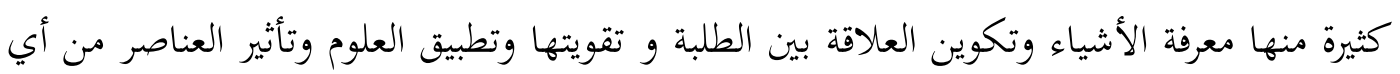

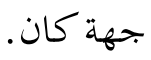

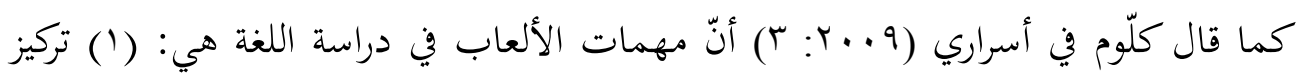

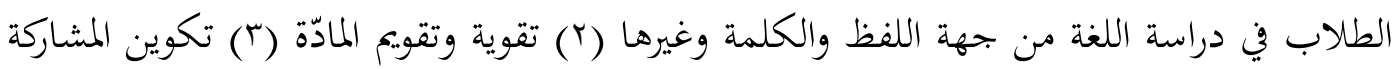

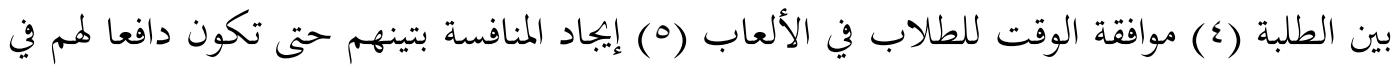

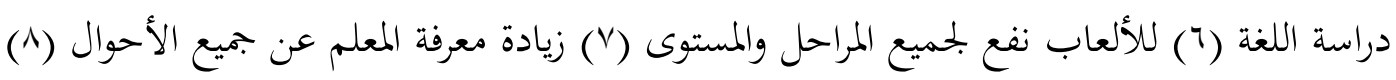
تشجيع الطلبة في دراسة اللغة.

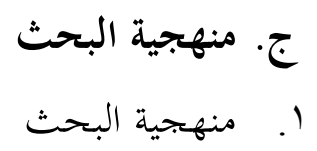

إنّ منهجية البحث الذي استخدمتها الباحثة هو المنهج الكيفي والكمي و المنهج الإجرائي. أي بعد أن توصف وتحلل الباحثة باستخدام أداة المقابلة والملاحظة ثمث تنتج الأرقام باستخدام 
الاختبار. وموضوع هذا البحث هو جميع الطالبات في مدرسة أبو ذر الثانوية قندال- داندير-

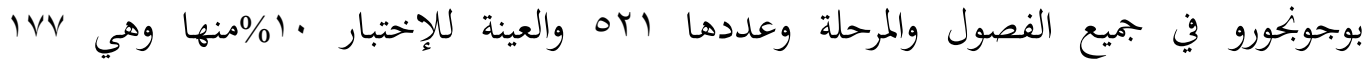
.(Sugiyono, 2010: 71)

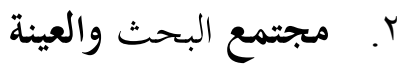

إن بحتمع البحث الذي اختارته الباحثة و كمصدر البيانات هي الطالبات في مدرسة أبو ذر

الثانوية قندال- داندير- -بوجونغارا في جميع الفصول والمرحلة وعددها ابه بالتفصيل أن الفصل العاشر VS VS والفصل الحادية عشرة r 1 ا ثم الفصل الثانية عشرة 170. والعينة للإختبار منها

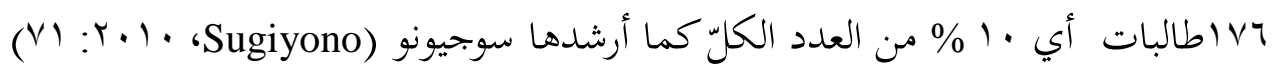

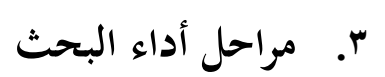

وأهداف هذا البحث هو للعلاج ولتحسين تعليم مهارة الكام في مدرسة أبوذر الثانوية.

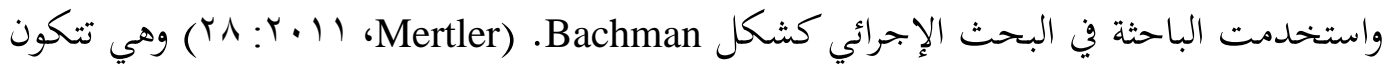
من أربعة خطوات : التخطيط, والتنفيذ, والملاحظة, والتقويم.

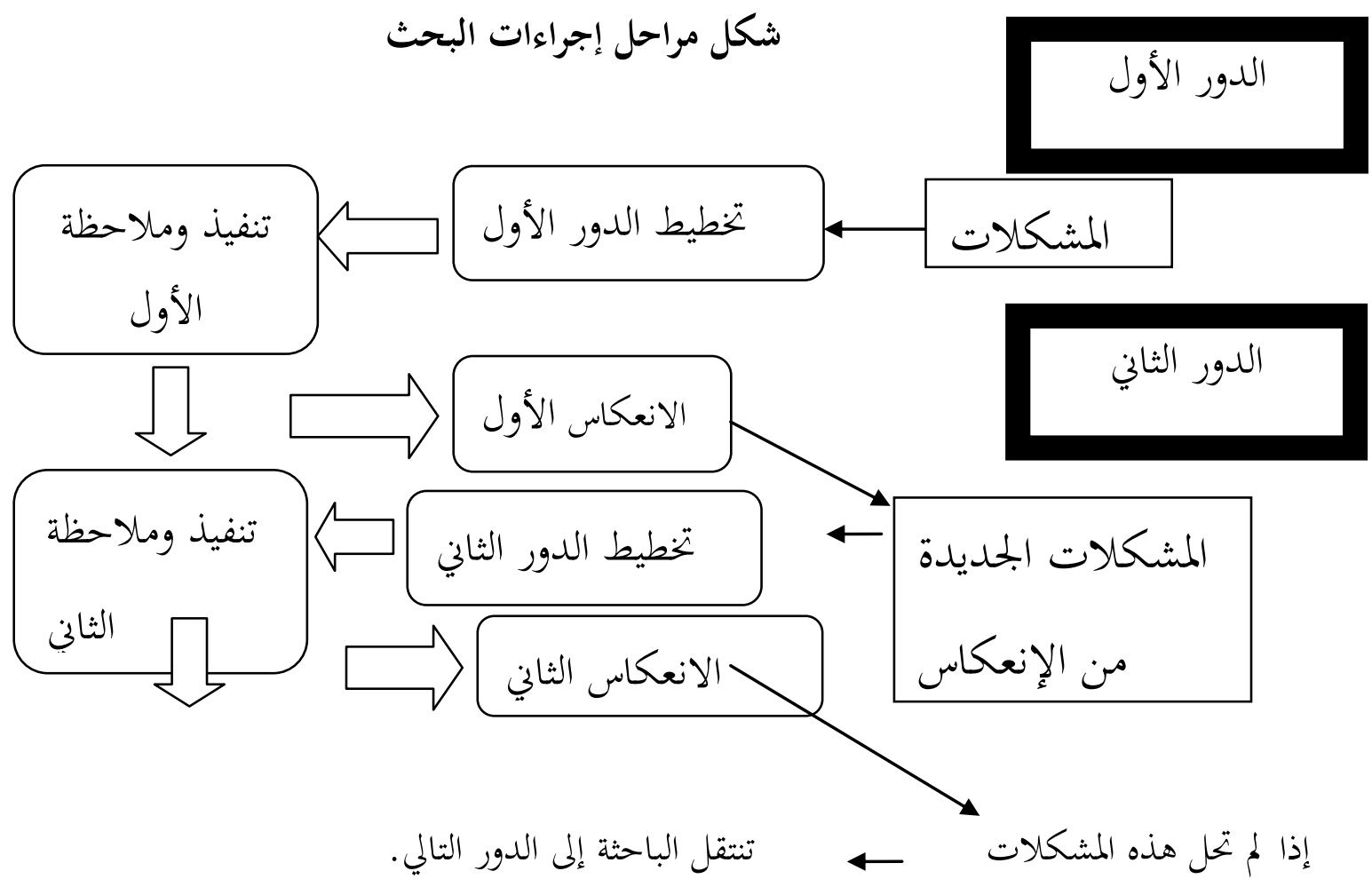




$$
\text { قامت الباحثة بتنفيذ الدروس الإضافية في مراحل الأشياء الآتية: }
$$

أ) استأذنت الباحثة من رئيس مدرسة أبوذرّ الثانوية عن تكوين البيئة العربية من خلاحل الإل الدروس الإية:

$$
\text { الإضافية. }
$$

ب) قابلت الباحثة إلى معلم اللغة العربية في مدرسة أبوذرّ الثانوية واستمعت إلى توجيهات

$$
\text { ج) وإرشادات وبيانات عن حال الطالبات في الفصول. }
$$

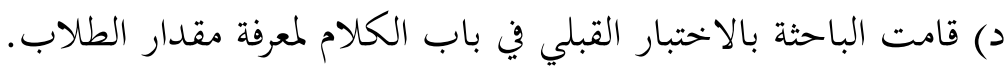

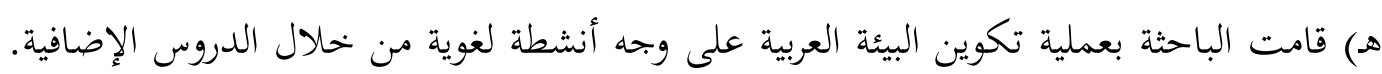

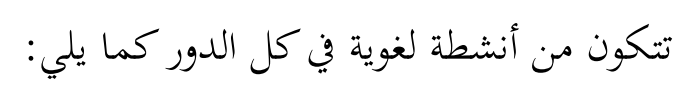

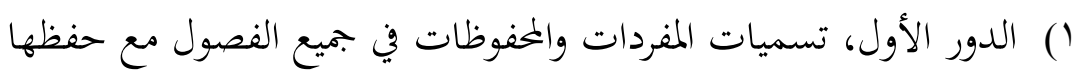

$$
\text { r }
$$

§) وأما المحادثة والخطابة من أهداف وجود البيئة حتى تمارس مرارا بين الطالبات والباحثة كل

$$
\text { يوم وكل وقت في كل الدور. }
$$

$$
\text { قامت الباحثة بملاحظة العميقة من خلال وجود البع البيئة العربية. }
$$

\begin{tabular}{|c|c|c|c|}
\hline العملية & التاريخ & 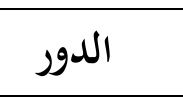 & الرقم \\
\hline تحديد المشكلة + اختبار قبلي & $r_{0}\left|T_{-} r_{-}\right| T^{\prime}$ & الدور الأول & 1 \\
\hline 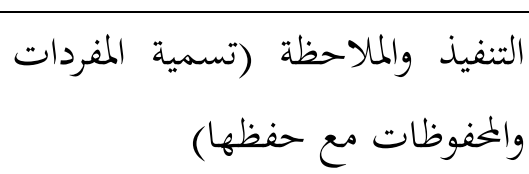 & T.IT-Y_rT & & \\
\hline اختبار بعدي + الانعكاس & $\left.r \cdot \mid r_{-} r_{-}\right)$ & & \\
\hline تحديد المشكلة الجحديدة & Y.17_r_o & الدور الثاني & $r$ \\
\hline التنفيذ والملاحظة (الغناء العربي) & $r \cdot 17-r_{-V}$ & & \\
\hline
\end{tabular}

ز) قامت الباحثة جمعت المظاهر التي يشمل على تأثير البيئة في عملية تعليم مهارة الكلام وتقوّم البئة أثناء الدراسة وغهايتها. وأما معيار الكفاءة هي بأن الطالبات يستطعن أن تتكلمن باللغة العربية جيدة وفصيحة كمادرسن في الفصول وفي الدروس الإضافية.

(1) الجدول

جدول تنفيذ إجراءات البحث 


\begin{tabular}{|c|c|c|c|}
\hline اختبار بعدي + الانعكاس & $r \cdot 1 \tau_{-} r_{-} \mid r$ & & \\
\hline تحديد المشكلة الجديدة & $\left.r^{\prime} \mid T_{-} r_{-}\right) \varepsilon$ & الدور الثالث & $r$ \\
\hline 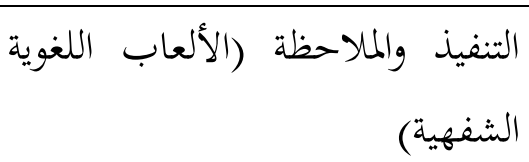 & $r \cdot 1 T_{-} r_{-} 17$ & & \\
\hline اختبار بعدي + الانعكاس & $T \cdot 10_{-} T_{-} T^{\prime}$ & & \\
\hline 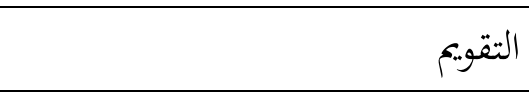 & T.10-T-YT & & \\
\hline
\end{tabular}

$$
\text { ع. ـأدوات جمع البيانات ومصادرها }
$$

ويأتي تفصيل مصادر البيانات في الجدول التالي:

\begin{tabular}{|c|c|c|c|}
\hline بنود البيانات المطلوبة & أدوات جمع & مصادر البيانات & رقم \\
\hline 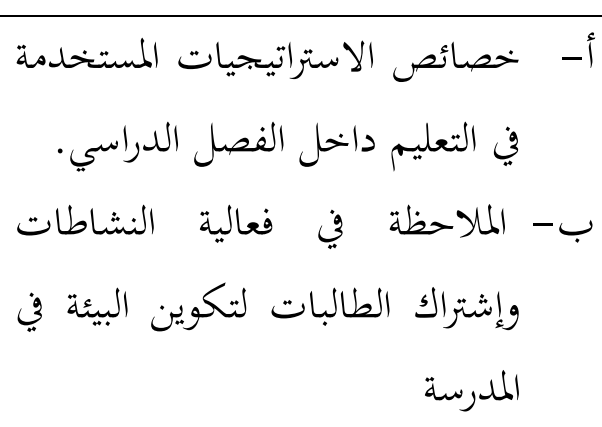 & الملاحظة & العمليات التعليمية & 1 \\
\hline 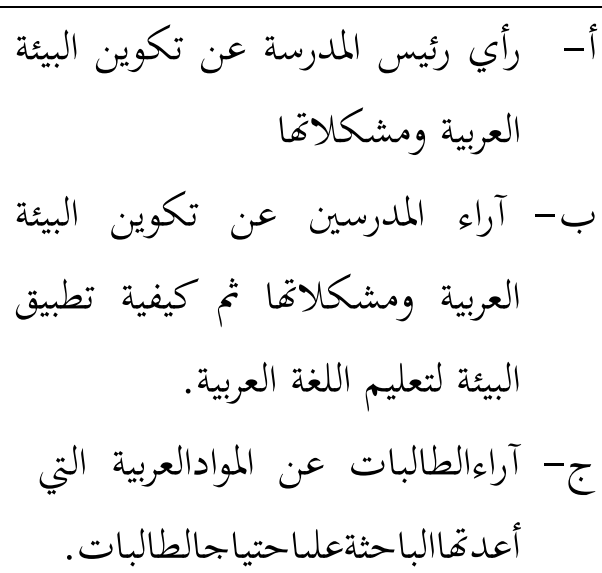 & المقابلة & 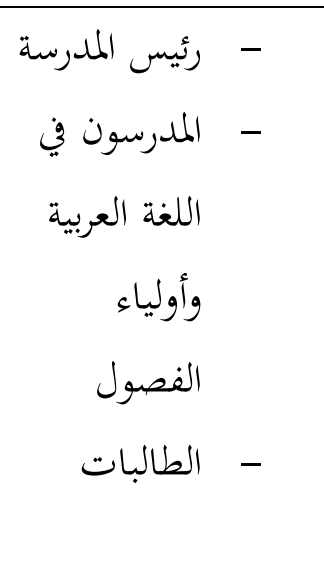 & $r$ \\
\hline
\end{tabular}




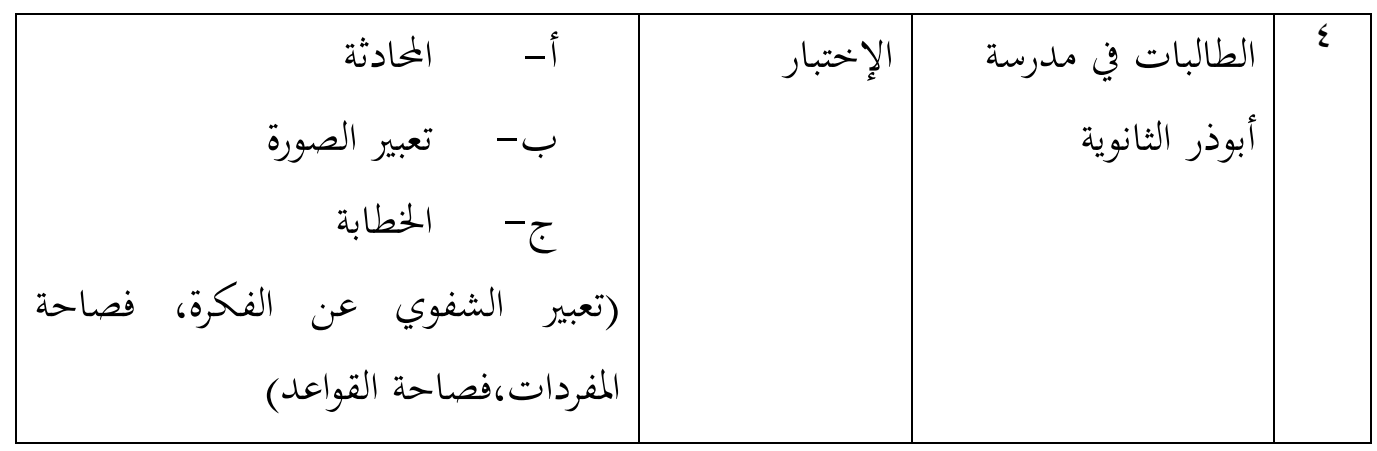

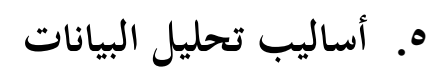

$$
\begin{aligned}
& \text { لمعرفة بخاح لمعيار من الإختبار } \\
& \mathrm{X}=\sum \frac{X}{N}
\end{aligned}
$$

$$
\begin{array}{rr} 
& \text { البيان } \\
\text { : } & \mathrm{X} \\
\text { : } & \sum x \\
\text { :عدد : عليجة الطلاب. } & \mathrm{N}
\end{array}
$$

وأما معيار بجاح الطلاب في الاختبار لكل مستوالنسبة عندها درجات، أما مستوى جيد

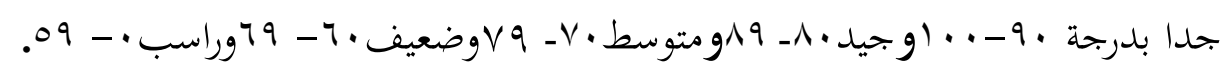

ولسهولة الباحثة لإعطاء النتائج للطالبات فياختبار مهارة الكلام قدمت معيار كما

يالي:الموجه عن طلاقة اللسان • ؛ درجاتثم فصاحة المفرداتهثثم درجاتفصاحة القواعده ب درجاتإذا

$$
\begin{aligned}
& \text { الطالبات التى حصلت جميعهم فالنتيجة ... } \\
& \text { T. أداء البحث وعرض البيانات }
\end{aligned}
$$

استخدمت الباحثة في البحث الإجرائي وهي تجري إلى ثلاثة أدوار قدر شهرين التي تتكون

عن أربعة خطوات : التخطيط، والتنفيذ، والملاحظة، والتقويم.

بعد أن تقابل الباحثة إلى رئيس المدرسة ومعلمة اللغة العربية لمعرفة احوال الطالبات وأنشطة

اللغوية في المدرسةخططت الباحثة عن أنشطة الدروس الإضافية، وتنفيذ هذا البرنامج كل يوم في

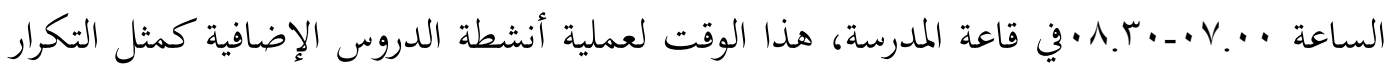
وحفظ المفردات ثم الغناء العربي ثم الألعاب الشفهية. وأما تسميات المفردات في جميع الفصول والأماكن المعينة قد دار قبل أسبوع بداية الحلقة. في الوقت المعين في كل الدور جمعت الباحثة الطالبات في كل المرحلة في القاعة، أما مرحلة الأولى تتكون عن مرحلة الأولى •V طالبة ثم مرحلة 
الثانية • V Vالبة ومرحلة الثالثة ا7 (17 طالبةوالباحثة عندها المصاحب والمصاحبة لملاحظة عملية أنشطة اللغوية للطالبات، كذلك معلمة اللغة العربية بتلك المدرسة شاهدت ولاحظت. وهذا الشرح والتفصيل عن احوال ونتيجة الطالبة في إشتراك الدروس الإضافية: أ) الدور الأول، قامت الباحثة بالاختبار القبلي في باب الكلام لمعرفة مقدار الطالبات. وبعد أن عرفت الباحثة عن نتيجة الاختبار القبلي أعطت الأنشطةلتسميات المفردات والمحفوظات مع حفظها وأحيانا أعطت الغناء العربي والألعاب الشفهية. قدر عشرة أيام بعد حفظ المفردات للطالبات أعطت الباحثة الإختبار البعدي، والنتيجة منه تدل على أن الدور الأول بدرجة راسب، والمعنى أن حفظ المفردات والمغفوظات لم تستطع لحل مشكلة كلام العربية. ب) الدور الثاني، قامت الباحثة بالاختبار القبلي في باب الكلام لمعرفة مقدار الطالبات بعد اشتراكهن في الدور الأول. وبعد أن عرفت الباحثة عن نتيجة الاختبار القبلي أعطت الأغنية العربية مع تكرار المفردات والمففوظات ثم مرة تلعب الألعاب الشفهيةقدر أسبوع كامل مع تطبيق المحادثة اليومية كل وقت وكل مكان. ثم نتيجة الاختبار البعدييدل على أن الدور الثاني بدرجة متوسط، والمعنى أن الغناء العربيى يعطي زيادة الحماسة للتعبير عن الكلمات شفويا أم تحريريا. ج) الدور الثالثقامت الباحثة بالاختبار القبلي في باب الكلام لمعرفة مقدار الطالبات والتقويم عن الدور الثاني. وبعد أن عرفت الباحثة عن نتيجة الاختبار القبلي أعطت كثرة من الألعاب الشفهية الكلامية بتكرار المفردات والغناء العربي. قدر أسبوع كامل تنتج درجة جيد للطالبات التى تدل بالاختبار البعدي. وأما المحادثة والخطابة من أهداف وجود البيئة حتى تمارس مرارا بين

$$
\text { الطالبات والباحثة كل يوم وكل وقت في كل الدور. }
$$

فأما الحاصل من ملاحظة الباحثةيدل على أن أنشطة لغوية في مدرسة أبو ذرّ لم توجد ولو كانت هذه المدرسة مملوء بأنشطة دينية ودرست فيها الطالبة علوم الدينية المتنوعة. ونشاط الطالبات باشتراكهن في الدروس الإضافية متازة أي أن الدروس الإضافية التى قدمتها الباحثة فعالة فالنتيجة من مقابلة الباحثة مع مدير المدرسة ومعلم اللغة العربية ومعظم الطالبات أهم يريدون وجود البيئة العربية، بل المشكلة لوجودها قلة المعلمين المتخصصين للغة العربية، وصعوبة وجود الأمر الجحيد تعني البيئة، والطالبات تحبن برنامج الدروس الإضافية التي قدمتها الباحثة وكلهم طبقواها بعد انتهاء البحث في تلك المدرسة. 
د. أهم نتائج البحث

انطلاقا من خلال الأسئلة وأهداف البحث واعتمادا على البيانات وتحليلها فقامت الباحثة لنية

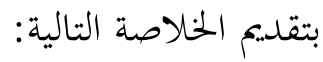

1. إن عملية محاولة تكوين البيئة العربية في مدرسة أبو ذر تجري بخلال الدروس الإضافية التى

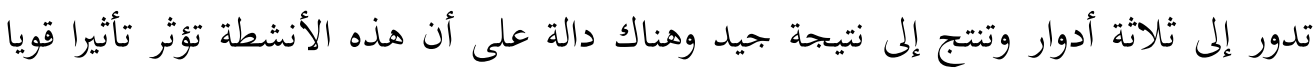

$$
\text { لترقية مهارة الكلام ووجود البيئة العربية. }
$$

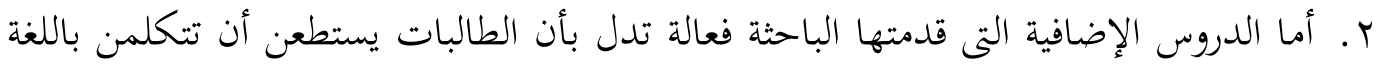

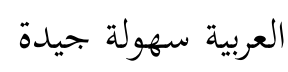

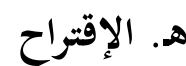

إن مهارة الكلام تتعلق و تثؤثر تأثيرا قويا بمهارة الإستماع ولأغما من نظرية اصطناعية أي بكما

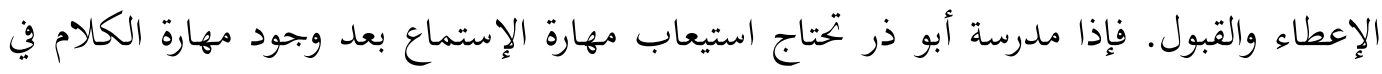

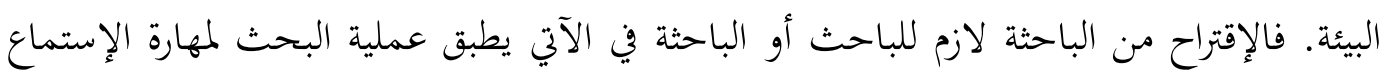

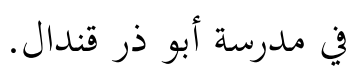

$$
\text { المراجع }
$$

المراجع العربية

ذوقان عبيدات وغيره. البحث العلمي. الرياض: دار أسامة للنشر والتوزيع. لو 199.

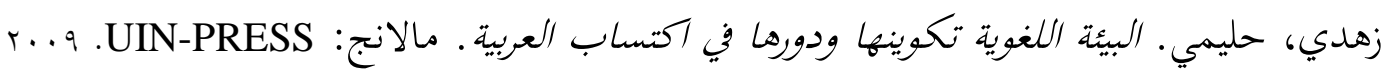
شحاتة، حسن."تعليم اللغة العببية بين النظرية والتطبيق" .طعيمة مزيدة ومنقحة: الدار المصدرية اللبنانية. دون السنة.

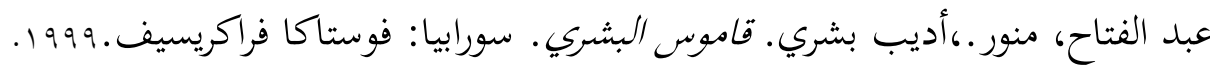

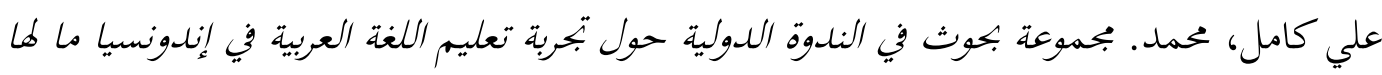
وما عليها. مالانق: The

حسين، محمود. سجل المرتمر الدولي الثاني.مالانق:Aditya Media Publishing ــ ا.ب الج المراجع الأجنبية

Abdulhak, ishak dan Ugi Suprayogi. Penelitian Tindakan Dalam Pendidikan Nonformal. Jakarta: Grafindo Persada. 2012

Adnan Latief, Muhammad.Tanya Jawab Metode Penelitian Pembelajaran Bahasa. Malang: UM PRESS. 2012. 
Arikunto, Suharsimi. Manajemen Penelitian.Jakarta:Rineka Cipta. 2005

Arikunto, Suharsimi.Prosedur Penelitian Suatu Pendekatan Praktik.Jakarta:Rineka Cipta. 2006

Asrori, Imam. Aneka Permainan penyegar Bahasa Arab.Surabaya: Hilal Pustaka. 2009

Febru Aries, Erna. Design Action Research. Malang: Aditya Media Publishing. 2010.

Hamid, Abdul. Mengukur kemampuan Berbahasa Arab. Malang: UIN PRESS. 2010

Izzan, Ahmad. Metodologi Pembelajaran Bahasa Arab. Bandung: HUMANIORA. 2009.

Kusumah, Wijaya dan Dedi Dwitagama. Mengenal Penelitian Tindakan Kelas. Jakarta: PT Indeks, 2011.

Mertler, Craig. Action Research. Yogyakarta: PUSTAKA PELAJAR.2011

Mujib, Fathul dan Nailur Rahmawati..Metode Permainan-Permainan Edukatif dalam Belajar Bahasa Arab.Jogjakarta: DIVA PRESS. 2011

Mulyasa, Penelitian Tindakan Sekolah. Bandung: Remaja Rosdakarya. 2012

Nata, Abuddin. Pemikiran Pendidikan Islam dan Barat. Jakarta: Raja grafindo Persada.2012.

Nurhadi dan Roekhan. Dimensi-Dimensi dalam Belajar Bahasa Kedua. Bandung: SINAR BARU. 1990.

Prayitno.Dasar Teori dan Praksis Pendidikan.Jakarta: Grasindo. 2009.

Rahadi, Moersetyo,. Sudrajat. Statistik Pendidikan. Bandung: Pustaka setia.2005

Sugiyono. Metode Penelitian Pendidikan: Pendekatan Kuantitatif, Kualitatif, dan $R \& D$, Bandung:Alfabeta. 2009.

Sugiyono. Statistika Untuk Penelitian.Bandung:Alfabeta.2010.

Wiriaatmadja, Rochiati. Metode Penelitian Tindakan Kelas. Bandung: PT Remaja Rosdakarya. 2007.

http://id.wikipedia.org/wiki/Ekstrakurikuler 